\title{
The Early Development of Neuroscience in Canada
}

\author{
Herbert H. Jasper
}

Can. J. Neurol. Sci. 1985: 12:221-229

A review of some of my personal recollections and research into the early development of neuroscience in Canada seems particularly appropriate at this time since we have just celebrated the 50th anniversary of the founding of the Montreal Neurological Institute which not only played a leading role in the early development of neuroscience in Canada, but also had considerable impact upon the development of both clinical and basic neuroscience throughout the world. The concept of the fusion of all the varied disciplines concerned with studies of the nervous system into one integrated "neuroscience" as we know it today in the Society for Neuroscience was not known when Dr. Penfield established the Montreal Neurological Institute with this in mind. He recruited colleagues in neurochemistry, neurophysiology, neuroanatomy, pathology, and neuropsychology to work in close association with clinical neurologists and neurosurgeons. Fellows were attracted from many countries for training in all of these disciplines and shared his dream of an integrated neuroscience aimed at a better understanding of the function of the nervous system underlying behaviour and mental function and more rational treatment of neurological diseases.

The inspiration, enthusiasm, and tireless determination of Dr. Penfield during the difficult times for the initial few years and during the most productive years of rapid growth following World War II, helped develop the Institute into a leading centre for research and training of neuroscientists in Canada, and also served as a catalyst for the rapid development of neuroscience in other centres throughout Canada and the United States. As one of my French colleagues has expressed it, the Institute was the "mother house" of neuroscience in Canada. It soon became a truly international institute of worldwide reknown.

I will consider, for purposes of this review, only the early years from about 50 years ago until the early 1960 's. The rapid development of neuroscience during the past 20 to 25 years probably is more familiar to most people, especially since the formation of the Society for Neuroscience. According to the 1984 Directory there are now over 500 Canadian members of this Society with very important contributions coming from all parts of Canada.

In order not to overlook important early developments in neuroscience with which I might not be familiar I have called upon several friends and colleagues to help gather information for purposes of this report. Pierre Bois and Philip Costin of the Medical Research Council have been particularly helpful in providing extensive reports of conference, surveys, and lists of grants covering much of the early work. I have also received valuable help from Hank MacIntosh regarding early developments in the Maritimes as well as in Ontario and Québec. Ted Sourkes has helped me review early developments in neurochemistry and neuropharmacology. John Szerb and Donald Hebb have provided what little information there was on early developments in the Maritimes. Jean Patterson, of the Department of Anatomy at the University of Manitoba, whom 1 had known as a brillant student at McGill and personal friend and classmate of my daughter, wrote several interesting letters concerning early developments in Charles Leblond's Department of Anatomy at McGill as well as early developments in Manitoba. Bill Gibson, Pat McGeer and Hugh McLennan provided interesting accounts of early developments in British Columbia.

It was clear from these surveys that there was little or no neuroscience of significance outside of Ontario and Québec 50 years ago, and very little in Ontario and Québec before the war, with a few notable exceptions. I will review briefly the results of this survey before concentrating on my own personal experiences at the Montreal Neurological Institute.

\section{The Maritimes}

John Szerb and Donald Hebb have assured me that there was

From a lecture given at the Annual Meeting of the Society for Neuroscience, Anaheim, California, October 11, 1984

Reprint requests to: Dr. Herbert H. Jasper, Université de Montréal, Faculté de médécine. Centre de recherche en sciences neurologiques

C.P. 6128. succursale A. Montréal, Québec. Canada H3C 3J7 
little or no neuroscience in the Maritimes until the early 1960's when John Szerb came from Gaddum's laboratory in Brabaham, England to continue his classical work on the liberation and function of acetylcholine in the brain, and Graham Goddard joined the Department of Psychology where he did his classical work on kindling. Dr. Kanai joined Dr. Weld in Physiology at Dalhousie in 1960 to study areas of vocalization in the brainstem of the cat.

Of course we all know that important neuroscientists came from the Maritimes, particularly Donald Hebb himself who has now retired to his home in Chester, Nova Scotia after a distinguished career at the Montreal Neurological Institute with Dr. Penfield, and as Director of the Psychology Department at McGill University for many years, culminating in being appointed Chancellor. Catherine Hebb, Donald's sister, is also well known for a distinguished career in neuropharmacology in England. There is also F.C. MacIntosh from Cape Breton who did outstanding work on the function and metabolism of acetylcholine in Sir Henry Dales' laboratories in London, before coming to McGill as head of the Department of Physiology where he continued his pioneer work on acetylcholine, including original measures of its liberation from cerebral cortex making use of techniques developed at the M.N.I. Dr. MacIntosh has also been of considerable help in recalling the work of some early pioneers in Ontario and Québec. Dr. William Feindel was another Maritimer who came to the MNI during his medical student days and eventually became its Director in 1972.

In spite of these slow beginnings, neuroscience has since flourished in the Maritimes. The 1984 Directory for the Society for Neuroscience lists $\mathbf{5 0}$ members from the Maritime Provinces.

\section{The Prairie Provinces}

There was very little neuroscience in the Prairie Provinces prior to the late 60 's and 70's, with a few exceptions brought to my attention by my friend Jean Patterson of the Department of Anatomy of the University of Manitoba in Winnipeg. Prof. V.H.K. Moorehouse of the Physiology Department at Manitoba had carried out some interesting studies on the effect of the sympathetic nervous system on muscle tone.

One of the most colourful characters was Professor Joseph Doupe who made outstanding contributions to the development of medical research in Manitoba and in the Department of Physiology, University of Pennsylvania with Prof. H.C. Bazett. During the war, he carried out important studies of peripheral nerve injuries under the auspices of the Medical Research Council of Great Britain. Returning to Manitoba in 1946 he became head of the newly formed Department of Medical Research and Professor of Physiology. He had a profound influence on the development of medical research and the training of many research workers in Manitoba and across Canada. He was a member of the first Medical Research Council and panel chairman to the Defense Research Board of Canada. In addition to his studies of nerve injuries and regeneration during the war, in 1933 and 1934, he published a series of 10 papers in the Journal of Neurology and Psychiatry entitled "Studies of Denervation".

In Saskatchewan, during the period 1955-1960, Dean Wendell McLeod attempted to establish a strong group of clinical neuroscientists in the medical school at Saskatoon by importing from Montreal, Allan Bailey and Donald Baxter in neurology; William Feindel, Joe Stratford, and Kenneth Paine in neuro- surgery, and George Olszewski in neuropathology. Unfortunately Dean McLeod did not get full support for his plans so that Feindel, Stratford, and Baxter returned to Montreal, and Olszewski went to Toronto to establish an important department of neuropathology there. In 1962-63 Joe Stratford and Don Baxter developed the beginnings of clinical and basic neuroscience at the Montreal General Hospital. It was not until somewhat later that significant neuroscience developed in Alberta, except for a few anatomical studies reported by Dean Rankin in the survey conducted by the National Research Council in 1938.

Although the prairie provinces developed their neuroscience late, they have made up for it recently with a total of $74 \mathrm{mem}$ bers of the Society for Neuroscience in 1984, 46 from Alberta alone, led by Robert G. Lee, editor of the Canadian Journal of Neurological Sciences, and Richard Stein, past president of the Canadian Association of Neuroscientists.

\section{British Columbia}

I have Professor William Gibson to thank for providing information concerning early developments in British Columbia for which he was largely responsible. In British Columbia, there was practically no neuroscience and no medical school 50 years ago. Dr. Frank Turnbull began practising neurosurgery in Vancouver in 1932 after training with Kenneth McKenzie in Toronto. He stimulated much interest in clinical neurological studies by showing that a number of patients in mental hospitals were actually suffering from brain tumours or other organic brain diseases. He also made important contributions to the study of nerve injuries during and after the war.

Significant research in the neurosciences did not begin until after the war with the establishment of the medical school in 1949. Dr. Arthur Crease, a McGill graduate, director of the provincial mental hospitals stimulated the development of research in the neurological sciences by the appointment of a director of research and the establishment of the Kinsman Laboratories first directed by William Gibson and later by Patrick McGeer and his wife Edith. Bill Gibson had trained with Sherrington and Ramón y Cajal, as well as at Queens Square Neurological Hospital in London, and at the Montreal Neurological Institute. He had also spent some time with Eccles in Australia, with whom he wrote an interesting personal biography of Sir Charles Sherrington, drawing upon his personal experiences while studying at Oxford.

Bill received most of his training with Dr. Penfield at the Montreal Neurological Institute. He was one of many fellows who got their start here and were instrumental in setting up important developments in neuroscience elsewhere in Canada. Other contributors to British Columbia from the MNI were Juhn Wada, Norman Auckland, William Fister, and Hugh McLennan who developed a very important neurophysiology laboratory in the Department of Physiology of U.B.C. Morton Low developed EEG, and was joined more recently by Andrew Eisen to establish an important team in clinical and experimental neurophysiology in Vancouver.

Adding great strength to the work in neurochemistry was the arrival in 1966 of Professor J.H. Quastel where he started a new career after retiring from his research unit at McGill where he had been since 1947. Quastel immediately attracted young coworkers and was joined by Dr. Sung of Taiwan and Dr. Woolf from 
Oxford, giving additional strength and depth to these important neurochemical laboratories.

\section{Ontario and Québec}

I would like now to return to neuroscience in Ontario and Québec where I am on more familiar ground. Here again there was very little neuroscience 50 years ago at the time of the founding of the Montreal Neurological Institute. Before describing in more detail the early work at the MNI and my own personal association with it, there were a few important developments which preceded it and which came to my attention only after my arrival in Montreal in 1938. I will also describe the circumstances surrounding my first acquaintance with neuroscience in Canada, and what induced me to leave God's country below the border and to migrate to Canada permanently at that time.

I have Hank MacIntosh also to thank for telling me of his discovery that the first Ph.D. in physiology in Canada was awarded to Frederick Hughes Scott in 1900, a student of Archibald B. McCallum who established Canada's first department of physiology at the University of Toronto in 1890. McCallum was also the first professor of biochemistry and first president of the National Research Council 1917-1920. After his retirement, he became the first professor of biochemistry at McGill. His pupil Fred Scott would qualify as a neuroscientist and was perhaps the first to postulate chemical transmission of the nerve impulse at the synapse, and to propose that chemical substances were transported from the cell body to the axonal terminals by axonal flow. These conclusions were drawn from his own histological and physiological studies of peripheral nerves and synapses in the spinal cord (1905-1906). MacIntosh believes that Scott was the first to propose chemical transmission at all synapses, not to be proposed again until Sir Henry Dale suggested in 1933 that this may be true. Scott's work was not generally accepted and all but forgotten even though published in Brain and in the Journal of Physiology at the time. He was a pioneer too much before his time, left Canada for an appointment in the United States and did not continue in neuroscience.

Shortly following the work of Scott there was graduated from the University of Toronto in 1903 a true pioneer in Canadian neurophysiology by the name of Fredrick Robert Miller who began his work in physiology at Cornell and at the Marine Biological Laboratory at Woods Hole. He returned to Toronto where he obtained his Bachelor of Medicine in 1907 and became demonstrator in physiology and biochemistry under Professor McCallum. He then studied in Germany and France before going to work with Sherrington in Liverpool 1911-1912. He then spent a couple of years as professor of physiology at McGill before returning to work again with Sherrington after he had been established at Oxford just before the First World War. His work on reflex deglutition in the decerebrate cat was published jointly with Sherrington in The Quarterly Journal of Physiology.

Miller was then appointed to the chair of physiology at the University of Western Ontario, an appointment which was to last 36 years. In 1947, he was appointed research professor of neurophysiology until he retired in 1950 .

Dr. Miller made use of strychnine as well as acetylcholine $(\mathrm{ACh})$ in an attempt to avoid the pitfalls of electrical stimulation in studying the function of areas such as the basal ganglia, the cerebellum, and centres for deglutition in the brainstem and cerebral cortex. Electrical recording was used in all of these studies to record not only the direct action of these substances, but also to record action potentials from the muscles activated by central stimulation. Recording was carried out with an early version of the cathode ray oscilloscope built by G.A. Woonton. The epileptic activation of the cerebral cortex by ACh was clearly described with George Stavraky. Miller also studied in detail the reflex organization of muscles of the forelimb isolated for individual recording of tension and action potentials, a problem suggested by Sherrington. He was able to show that all reflex adaptations were present in the decapitate cat as well as in midbrain and bulbar preparations.

After returning from England in 1932 where he received his Fellowship in the Royal Society, Professor Miller was asked by the Canadian Medical Association to deliver a series of lectures before provincial and local medical societies across Canada from Sudbury to Vancouver. The subjects of his lectures included "one hundred years of functional neurology, motor and sensory localization in the cerebral cortex, advances in electrophysiology with special reference to action potentials in muscle and nerve, and to electrocardiography". His extensive studies of the physiology of the cerebellum have also been widely quoted.

George Stavraky who collaborated with Miller in many of these studies, received some of his training at the Montreal Neurological Institute where I had the pleasure of meeting him in 1938. After returning to Western, he continued his studies of the brain providing evidence for denervation sensitization as a mechanism enhancing the excitability and tendency to epileptic discharge in cerebral cortex.

There were two other important pioneers at Western of importance to the early development of neuroscience in Canada: James Rossiter in neurochemistry and Murry Barr in anatomy. Rossiter's principal contributions were in the field of neurolipids and the chemistry of myelin, while Murry Barr is well known for his quantitative studies of synapses and his identification of the X-chromosome or Barr body among other contributions to neuroanatomy. Rossiter and Barr were instrumental in stimulating important developments in neuroscience at Western which continue today, particularly with Mogenson and Vernon Brooks in physiology, Arthur Hudson, from the MNI in experimental neurology, and with Barnett and Drake in neurology and neurosurgery.

Another important figure in the early development of neuroscience at Western is James A.F. Stevenson who received his MA degree at McGill in psychology the same year I arrived in 1938. We were also associated as students in the McGill Medical School where he graduated in 1942 (I graduated one year later, in the class of 1943) and in the RCMC during the war. Jim studied at Yale in physiology and physiological chemistry, to return to Western as Head of the Department of Physiology in 1951. His research contributions were in the field of hypothalamic function and nutrition. His influence was extended through his services as editor of the Canadian Journal of Physiology and Pharmacology, President of the Canadian Physiological Society, editor of the newsletter of the International Union of Physiological Societies and active member of the American Physiological Society. He also served as Dean of Graduate Studies at Western, member of Senate, and Board of Governors. There is an annual lectureship in his honour, given recently by Pat McGeer of U.B.C. 
There was very little neuroscience at Toronto until the 1940's when things developed with John Scott and John Goodwin in electrophysiology and electroencephalography, J.C. Richardson, in neurology, and Kenneth McKenzie and Harry Botterell in neurosurgery. Don Solandt was professor of Biophysics and Physiology in the early days after receiving post doctoral training with A.V. Hill in London, England. I met Harry Botterell first when he was working with John Fulton in the physiology department at Yale while I was nearby at Brown University in Providence, Rhode Island. We became friends soon after I arrived in Canada and were associated in the RCAMC during the war. He is remembered at Queens for his many contributions as Dean of Medicine and was commemorated by naming the new medical research building "Botterell Hall".

I would like now to turn to a more personal account of how I first learned of neuroscience in Canada about 50 years ago, chiefly because of the ceremonies surrounding the opening of the Montreal Neurological Institute in 1934 and a visit from Dr. Penfield to lecture at Brown University shortly thereafter. I first met Dr. Penfield in 1936 when he came to Brown University as a visiting lecturer. I had just established experimental and clinical neurophysiology laboratories at the Bradley Hospital with a long term grant from the Rockefeller Foundation, including laboratories of clinical and experimental electroencephalography. I was very much impressed with Dr. Penfield's lecture describing responses of fully conscious epileptic patients to local electrical stimulation of the exposed cerebral cortex during explorations for the surgical treatment of focal epilepsy.

I was as much impressed by Penfield himself as by his interesting lecture. He had worked in the Cajal laboratories in Madrid and with Sherrington in Oxford during his Rhodes Scholarship during the First World War. His interest in the surgical treatment of epilepsy seemed to be motivated as much by the opportunities it afforded for physiological studies of the human brain as for the cure of epilepsy.

Penfield came out to the Bradley Hospital to see my laboratories and to witness for the first time the recording of an electroencephalogram of an epileptic patient with an apparent cortical focus of spike discharge. He was amazed but skeptical. He said he would believe it if he could expose the cortex and find the focus where the EEG had indicated it should be. $\mathrm{He}$ then agreed to operate on a couple of my epileptic patients who showed a clear spike focus in the EEG if I would bring them to Montreal. I not only brought two patients, but also a portable EEG apparatus in the back of my car which could be set up in the operating room to record from the exposed cortical surface during the operations. I carried skis on the top as well for it was also the excellent skiing in and around Montreal that interested me, in those days, almost as much as the Montreal Neurological Institute. Fortunately, Penfield was also a keen sportsman and invited me to join him and his staff for week-ends of skiing when I came to Montreal in the winter. In the summer, we went to his farm on Lake Memphramagog where I took part in the sailing races held every Saturday. Penfield's sailing dinghy "The Astrocyte"' is shown in Fig. 1.

During the next year, I commuted almost every week from Providence to Montreal, driving at night in all kinds of weather in order to fullfil my teaching, research, and clinical obligations in Providence while beginning collaboration with Dr. Penfield and colleagues in Montreal. Fortunately, in one of the two trial patients I brought to Montreal we did find a clear focal lesion

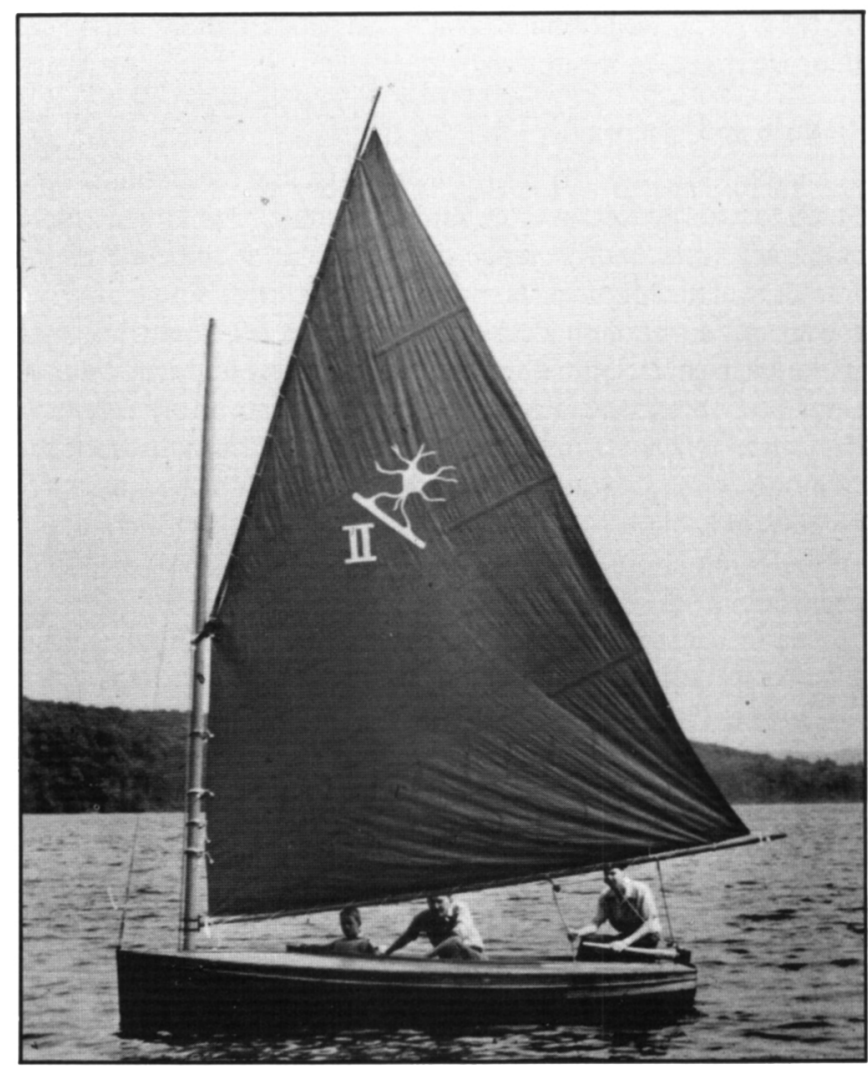

Figure I - Dr. Penfield's sailing dinghy "Astrocyte II".

where the EEG had indicated it should be, and was confirmed by direct recording from the exposed cortex. The lesion was successfully removed. The patient was a young boy at the time. I saw him recently while visiting Brown. He had become a very successful business man and had been free of seizures for over 40 years since the operation.

I was then asked in 1937 to join Penfield and colleagues at the MNI providing they could give me adequate laboratory space and research funds. Dr. Penfield managed to get my Rockefeller grant transferred to $\mathrm{McGill}$ and raised private funds for the construction of an addition to the Institute to house the new laboratories. Thus began, in 1938, a long and productive collaboration and friendship which finally resulted my becoming a Canadian citizen after serving in the Canadian Army Medical Corps during the war.

Our new laboratories were formally opened in the winter of 1938-39. The opening ceremonies were attended by many of the early workers in electroencephalography at the time (Fig. 2). After visiting the new laboratories, we proceeded to Domaine d'Esterel in the Laurentian mountains where we had a scientific meeting intermingled with skiing and a downhill race. This was the first of our annual EEG Ski meetings which have been held in the Laurentians ever since, now under the auspices of the Eastern EEG Association. They were so successful, drawing neuroscientists and electroencephalographers from all parts of the United States, that they gave birth to other such ski meetings in Europe and in the United States. A photograph of the Institute as it appeared in 1940 is shown in Fig. 3.

Upon arriving in Montreal, I found a small closely knit community of enthusiastic dedicated workers, all participating in 


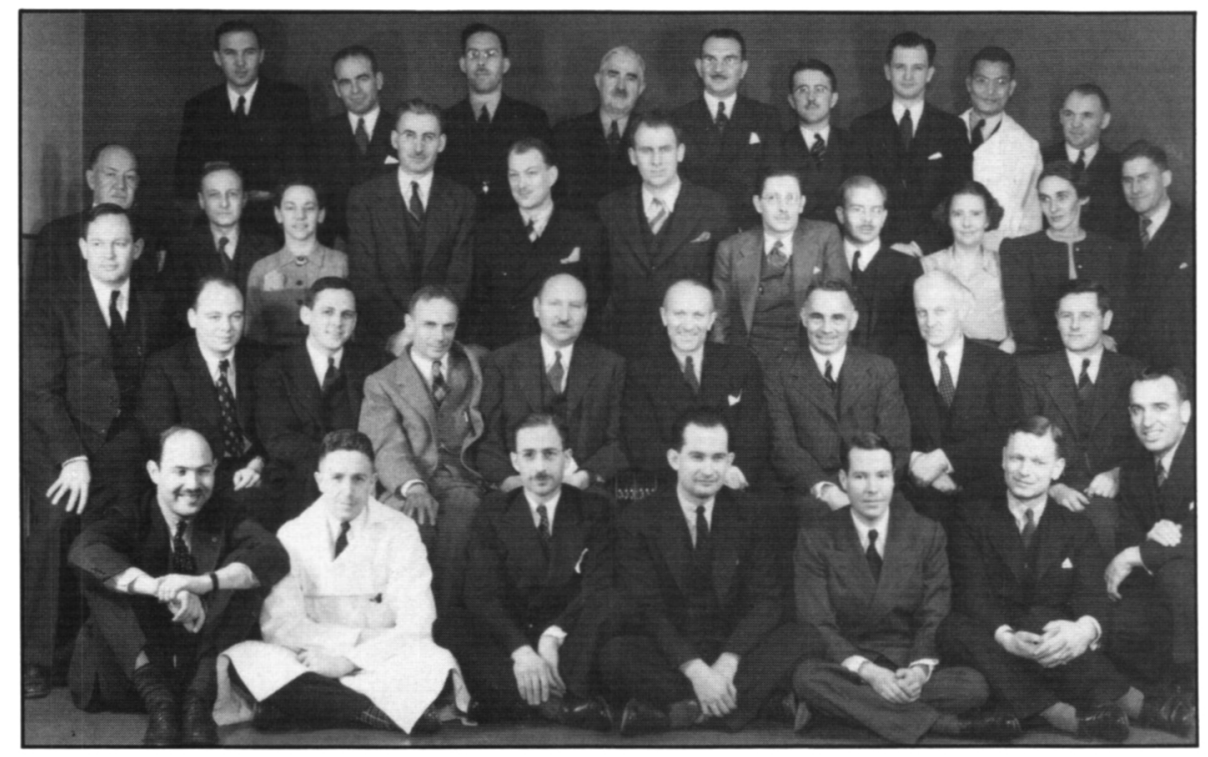

Figure 2 - Participants in opening ceremonies for the laboratories of electrocncephalography and neurophysiology at the Montreal Neurological Institute in February, 1939.

Front row: $R$. Schwab, S. Humphrevs, $H$. Jasper, A. Cipriani, J. Hobart.

W. Cone.

Second row: L. Nims, D. Lloyd. J. Hughes, S. Cobb. N. Harvey, W. Penfield, A. Loomis. A. Forbes, H. Davis.

Third row: $C$. Russell, N. Peterson, $M$. Rheinberger, J.Baldes, W. Hall. T. Erickson. J. Goodwin. T. Case, M. Harower, Mrs. R. Schwab, A. Elididge.

Fourth row: H. Andrew's, J. Evans, D. Solandt. A. McKar, J. Kershman. Lindsley, C.L. Lee, A. Divorkin.

ward rounds, working in the operating rooms and laboratories, each applying his special knowledge and skills to investigation of common problems of the structure and function of the nervous system. Each patient was considered a challenge to our understanding of the normal functional organization of the nervous system, as well as the pathology of its diseases. Laboratories of neurochemistry, neurophysiology, neuropathology, and neuroanatomy worked side by side with the neuropsychologists, clinical neurologists and neurosurgeons who, in most cases, were also active laboratory workers. We were soon joined by a group of excellent French neurologists, particularly Jean Saucier, Romeo Amyot and Antonio Barbeau, who had already established a good neurological service in the French hospitals in Montreal. The Institute provided a stimulating meeting ground for weekly conferences attended by neurologists of the French tradition and those of the British tradition, led by Colin Russell, Donald McEachern and Francis McNaughton. Most important was the growing numbers of both young French and English fellows in training from Montreal and across Canada and the United States. Fellows were soon coming from many other countries throughout the world, from China, Australia, Japan, Mexico and South America, as well as from Great Britain, Europe, India, the Middle East, with a few later coming from the Soviet Union. The Institute soon became not only a focal point for the development of neuroscience and the training of neurologists and neurosurgeons in Canada and the United States, but also a truly International institute of worldwide renown.

At the 25th Anniversary, celebrated in 1959, there were about 300 fellows who had trained or worked at the Institute as visiting scientists for at least one year, including research workers in neuroanatomy, neuropathology, neurophysiology, neurochemistry, neuropsychology, neuroradiology, and electroencephalography as well as in clinical neurology and neurosurgery. Nearly all of the fellows were actively engaged in basic research as well as in clinical training during the sejour at the Institute. A

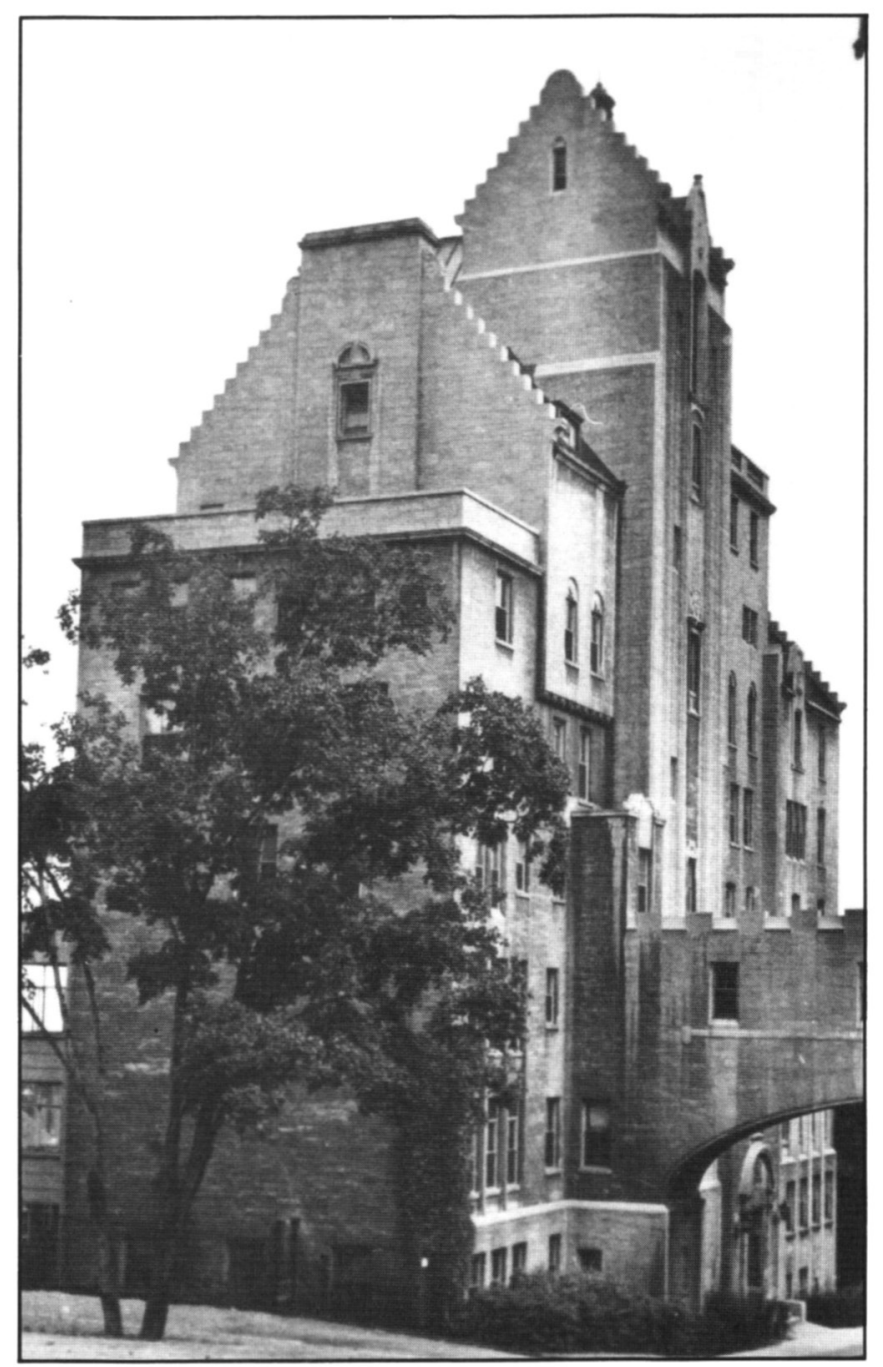

Figure 3 - The original Montreal Neurological Institute as it was in 1940. 
few of the most early fellows are listed below:

Dorothy Russell: of London England, later to become one of the world's leading neuropathologists.

Joseph Evans: of the United States, later to become professor of neurosurgery at Cincinnati and the University of Chicago. Co-authored studies of frontal lobe in man with Penfield.

Jerzy Chorobski: of Warsaw, Poland, to become first professor of neurosurgery, University of Warsaw.

Arne Torkildson: of Norway, to become professor of neurosurgery at the University of Oslo, developed ventriculocysternostomy for treatment of hydrocephalus.

Theodore Erickson: neurosurgeon and neurophysiologist from the United States, carried out important studies of experimental epilepsy with $H$. Jasper became chief of neurosurgery at the University of Wisconsin, Madison. Co-authored first book, Epilepsy and Cerebral Localization with Penfjeld (1941).

Edwin Boldrey: from the United States, published with Penfield early studies of motor and sensory representation in the cerebral cortex in man as shown by electrical stimulation, and studies of the spread of seizures in man (1937-1939). Became professor of neurosurgery at the University of California School of Medicine in San Francisco.

Francis McNaughton: Canadian, neuroanatomist and neurologist became director of neuroanatomical laboratories and later chief of the department of neurology at McGill University, and beloved teacher of many generations of Institute Fellows and Medical Students.

Arthur Elvidge: Canadian, Ph. D. in neurophysiology, and whimsical staff neurosurgeon/neuropathologist at the Institute.

William Gibson: Canadian, neurohistologist (student of Cajal and Hortega), Rhodes Scholar with Sherrington and Osler at Oxford, studied neurology at Queen Square, London, and with John Eccles in Australia with whom he wrote a biography of Charles Sherrington. Leader in the development of neuroscience and Professor of the History of Medicine at the University of British Columbia, now Chancellor of the University of Victoria, B.C.

André Cipriani: from the West Indies, brilliant biophysicist, engineer, and MD; built first electronic and EEG apparatus at the Institute, together with apparatus for recording cerebral blood flow, and other special apparatus for war research, became chief of radiobiology of the Atomic Energy Research Laboratories at Chalk River.

John Kershman: English born Canadian, neuropathologist and electroencephalographer, collaborated with H.J. in publication of The EEG Classification of the Epilepsies (1941), died during meeting of the American EEG Society in Atlantic City, Kershnan Lecture in his honour at Annual Meetings of the Eastern EEG Association.

Webb Haymaker: from the United States, neuropathologist trained at the MNI before the war, became chief of neuropathology at the U.S. Army Institute in Washington D.C. and neuropathologist of NASA.

Theodore Rasmussen: son of the neuroanatomist Prof. A.T. Rasmussen of the University of Minnesota. Neurosurgical and EEG Fellow at the Institute, coauthored with Penfield "The Cerebral Cortex of Man" (1950), served with the U.S. Army in Burma during the war, returned to the University of Chicago and then back to the Institute to become its Director following Dr. Penfield's retirement in 1954.
Martin Nichols: from Scotland, to return to become Neurosurgeon-in-Chief at Aberdeen.

William Lister Reid: from Australia, to return to become key figure in the development of neurosurgery in Australia.

Kalman von Santha: Rockefeller Fellow from Hungary, to become leader in neurology and neurosurgery in Budapest.

J. Sloan Robertson: Rockefeller Fellow from Scotland, to establish Institute of Neurological Sciences at Glasgow.

Guy Odom: from the United States, later to become Neurosurgeon-in-Chief at Duke University.

Donald Hebb: Canadian psychologist from Nova Scotia, student of K.S. Lashley, published classical studies of the frontal lobe with Penfield. He carried out studies of sensory deprivation and later published his classical text, The Organization of Behaviour, as director of the Department of Experimental Psychology at McGill University and later to become its Chancellor.

Miguel Prados: from Madrid, refugee from Spanish Civil War, student of del Rio/Hortega, carried out important studies of cerebral oedema and effect of cortisone on its alleviation in collaboration with a young medical student by the name of William Feindel who later became a neurosurgeon and director of the Institute.

Robert Pudenz: from the United States, resident in neurosurgery with Cone and Penfield, and neuropathologist, to become neurosurgeon and director of research laboratories of the Huntington Hospital in Pasadena Cal. where he developed the shunt valve system for treating hydrocephalus and other neurosurgical techniques including experimental prosthesis for the blind.

Yi-Cheng Chao: Rockefeller Travelling Fellow from China, became director of the Peking Neurosurgical Institute and leader of the early development of clinical neuroscience in China.

Roy Swank: Commonwealth Fellow from the United States (with Derek Denny-Brown in Boston) carried out important studies of Vitamin B deficiency, experimental epilepsy, and multiple sclerosis. Became Neurologist-in-Chief at the University of Oregon Medical School in Portland.

Claude Bertrand: Rhodes scholar with William Feindel at Oxford and French-Canadian neurosurgeon, worked with $\mathrm{H}$. Jasper during the war on the use of electromyography for the diagnosis of nerve injuries, later to lead in the development of neurosurgery and original methods of stereotaxic exploration of the human brain at the Notre-Dame Hospital of the University of Montreal.

Arthur Ward Jr.: Neurophysiologist from Yale who came to train in neurosurgery with Drs. Penfield and Cone, to become Prof. of Neurosurgery at the University of Washington in Seattle, leader of a team of neuroscientists using advanced microelectrode techniques for studies of basic mechanisms of the epilepsies.

William Fields: from the United States, neurologist, carried out important studies of seasickness for the Canadian Navy during the war, became chief of neurology at Baylor University in Houston, Texas.

K.A.C. Elliott: from South Africa, via Cambridge England and the Psychiatric Institute of the University of Pennsylvania. Recruited for war-related research on cerebral oedema, and for research on neurochemical mechanisms of epileptic brain tissue, studying human cortical tissue excised by 
Dr. Penfield during operations on focal epileptic patients. Established leading neurochemical laboratories at the Institute, discovered inhibitory properties of gammaaminobutyric acid (GABA), became Prof. of Biochemistry and Head of Department at McGill University.

William Feindel: from Nova Scotia, Rhodes Scholar, research in neuroanatomy with Weddell in Oxford, came to MNI in 1942 as medical student working with Miguel Prados on control of brain edema, EEG and neurophysiological research later, became neurosurgeon in chief in Saskatoon before returning to the $\mathrm{MNI}$ in 1959, to become Institute Director in 1972, succeeding Dr. Rasmussen.

This is only a partial list of some of the leading figures in development of clinical and basic neuroscience at the Montreal Neurological Institute up to the end of the Second World War. During the war we were all engaged actively in war-related research: physiological studies of "black out" due to high " $G$ " in combat flying which resulted in the development of the Canadian anti-" G"' suit; studies of motion sickness resulting in the anti-seasickness pill used in the invasion of Normandy on " $D$ " day; studies were performed for the treatment of burns, of the effect of high altitude flying on head injuries, and air ambulance services were developed in the Medical Corps; studies were conducted into the use of antibiotics in the treatment of infections of the CNS, and the convulsant properties of some sulpha drugs and penicillin were shown; improved treatment of cerebral oedema was developed; studies of the diagnosis and treatment of nerve injuries were carried out; the EEG was applied to the screening of pilots for the Air Force. We continued throughout the war our major interest in experimental and

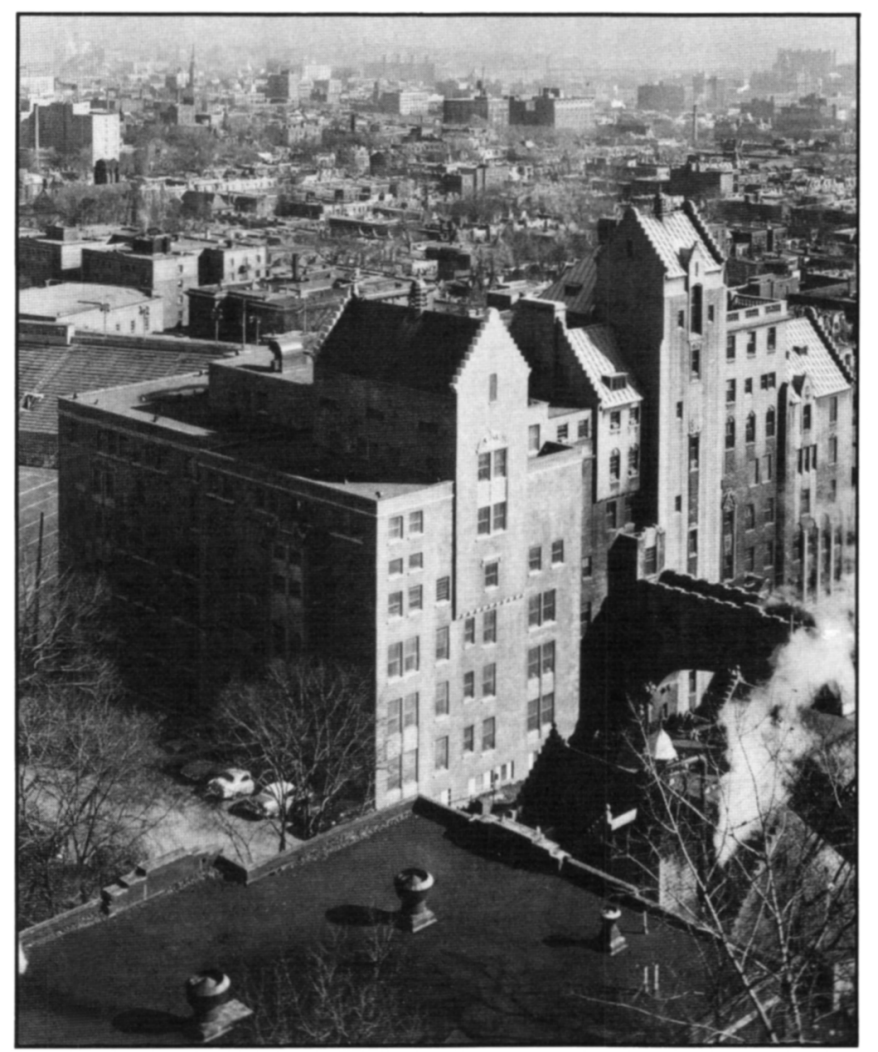

Figure 4 - The MNI with the addition of the McConnell Pavilion opened in 1953 clinical studies of basic mechanisms of the epilepsies.

Following the war there was a great influx of post doctoral fellows and visiting scientists from Canada, the United States, and from many other countries. Another wing was added to the Institute, the McConnell Pavillon opened in 1953, almost doubling the clinical and research facilities (Fig. 4). I can mention only a few of the clinical and basic neuroscientists who joined us for a year or more during this period of rapid expansion, leading up to the 25th anniversary celebrations in 1959.

The first visiting scientist to arrive following the war, in 1947 , was a distinguished neuroanatomist from Holland, Jan Droogleever Fortuyn, whose Rockefeller Fellowship had been postponed because of the war. In collaboration with H.J. he studied the physiology of thalamo-cortical relations, developing the concept of the thalamic reticular system and its role in regulating the electrical activity of the brain and acting as a pacemaker for the bilateral wave-and-spike EEG pattern of petit mal epilepsy. During the next 12-15 years, the laboratories of clinical and experimental neurophysiology were joined by many research fellows and visiting scientists. Many electrophysiological studies were carried out on epileptic patients in the EEG Department and on the exposed cortex with Dr. Penfield in the operating room during surgical exploration for focal epilepsy.

Some of the fellows working in these and associated laboratories during this period were as follows:

Canada: Gilles Bertrand, Murry Bornstein, Jean-Pierre Cordeau, Guy and Annie Courtois, Ben Doane, Frank Echlin, William Feindel, David Hubel, Robert Martin, Hugh McLennan, Seth Sharpless, Joe Stratford, Bryce Weir

United States: George Austin, Charles Branch, William Caveness, Charles Cure, David Daley, Herman Flanigan, Tony Gorman, John Hanbery, John Jane, Robert Knighton, Phanor Perot, Dan Pollen, Alfred Pope, Mark Rapport, Ted Rasmussen, Richard Rovit, Julius Stoll, Lever Stewart, Keasley Welch, and William Wilson

France: Genevieve Arfel, Henri Gastaut, Gabriel Mazars Robert Naquet and Bernard Pertuiset

Italy: Cosimo Ajmone-Marsan, Gastone Celesia, F. Coceani and G. Ricci

Sweden: David Ingvar and Herbert Silvenius

Norway: B.R. Kaada and Kristian Kristiansen

Greece: Odoros Economos and Costa Stefanis

Turkey: Kenen Tukel

Japan: Witsuru Ebbe, Kitsuya Iwama, Ikuko Koyama and S. Yamamoto

Poland: L. Stepien and J. Majkowski

Switzerland: Pierre Gloor and Rudolph Hess

Mexico: C.J. González

Holland: Jan Droogleever-Fortuyn and Otto Magnus

Belgium: Jan Gybels

Spain: Louis Marco and Miguel Prados

It is apparent from the above that the majority of fellows working in the neurophysiology and EEG Departments during the early years at the Institute were from Canada and the United States, but representatives from many other countries gave a truly international flavour to our work. International relations were enhanced when $H$. Jasper became the first president of the International Federation of Societies for Electroencephalography and Clinical Neurophysiology and Editor-in-Chief, as well as publisher of its Official Journal in Montreal, "The EEG Journal", and first president of the American EEG Society. 
Somewhat later (1960-62) H. Jasper also became the first Honorary Executive Secretary of the International Brain Research Organization (IBRO) which was incorporated in 1961 by Act of Parliament in Ottawa.

The laboratories of neurochemistry also flourished during this time, under the direction of K.A.C. Elliott, in association with Hania Pappius and Leon Wolfe. Donald Tower received his training here with a 5 year Markle Fellowship in neurochemistry, where he began his classical studies of the neurochemistry of epilepsy, which he carried on when he became neurochemist of the NINCDS in Bethesda. Other prominent fellows were Hugh McLennan, Nico van Gelder, Ernst Florey, R.I. Noble, Marion Birmingham, Jim Webb, Al Bazemore, Francis deFeudis, Franz Hobbiger, Igor Klatzo, Roy Swank, Jim Crossland and many others.

In neuroanatomy and neuropathology was the outstanding work of George Olszewski and Igor Klatzo, who were refugees from Poland, having studied with Oscar and Cecile Vogt in Germany. Olszewski's cytoarchitectonic studies of the diencephalon and brainstem in the monkey and humans (in collaboration with Donald Baxter) and his detailed studies of thalamocortical relations with Blaine Nashold are still classics in the literature. Olszewski then turned to neuropathology, establishing laboratories at the University of Saskatchewan while William Feindel was there in neurosurgery, then moving to the University of Toronto where he was just getting started before his untimely death. Ramón y Molinar was also engaged in his classical studies of the dendritic organization of the brain in the laboratories of neuroanatomy at the MNI in the decade following the war, and subsequently at the University of Sherbrooke, Québec.

When the United States National Institutes of Health were organized in 1949, the Institute of Neurology was staffed almost entirely by fellows trained at the MNI, including the following:
Milton Shy (neurology), Maitland Baldwin (neurosurgery), Cosimo Ajmone-Marsan (electroencephalography and neurophysiology), Cho Lu Li (neurosurgery and neurophysiology), Igor Klatzo (neuropathology), John Van Buren (neurosurgery), William Caveness (neurophysiology), Anatole Dekaban (developmental pathology), John Lord (neurology), and Donald Tower (neurochemistry) later to become Director of the NINCDS succeeding Richard Masland who was also a fellow in neurophysiology at the MNI for one year.

There were other important developments in neuroscience at McGill and the University of Montreal in the decade following the war. Professor F.S. MacIntosh returned to Canada from Sir Henry Dale's laboratories in London to take the chair of Physiology at McGill and to continue his classical studies of acetylcholine. He recruited several neuroscientists, including Ben Burns, Bernice Grafstein, Richard Birks and Kris Krnjević whose classical intra and extracellular microiontophoretic studies of neurotransmitters and ionic mechanisms in single cells of the cerebral cortex, hippocampus, and sensory nuclei in the brain, including the use of ion specific microelectrodes represent major advances in our understanding of the synaptic and cellular organization of the CNS. Professor Maclntosh was the principal organizer of the International Congress of Physiological Sciences held in Montreal in 1953, at which time we had also the opening of the new McConnell Pavilion of the MNI, and the Satellite Laurentian Symposium on "Brain Mechanisms of Consciousness" which brought together leading world authorities to discuss the importance of the brainstem reticular system in the organization of the higher integrative functions of the brain.

It was also in 1953 that Dr. Penfield and I completed a summary of our clinical and electroencephalographic studies of hundreds of epileptic patients with results of electrical stimulation and recording from the exposed cortex during neurosurgi-

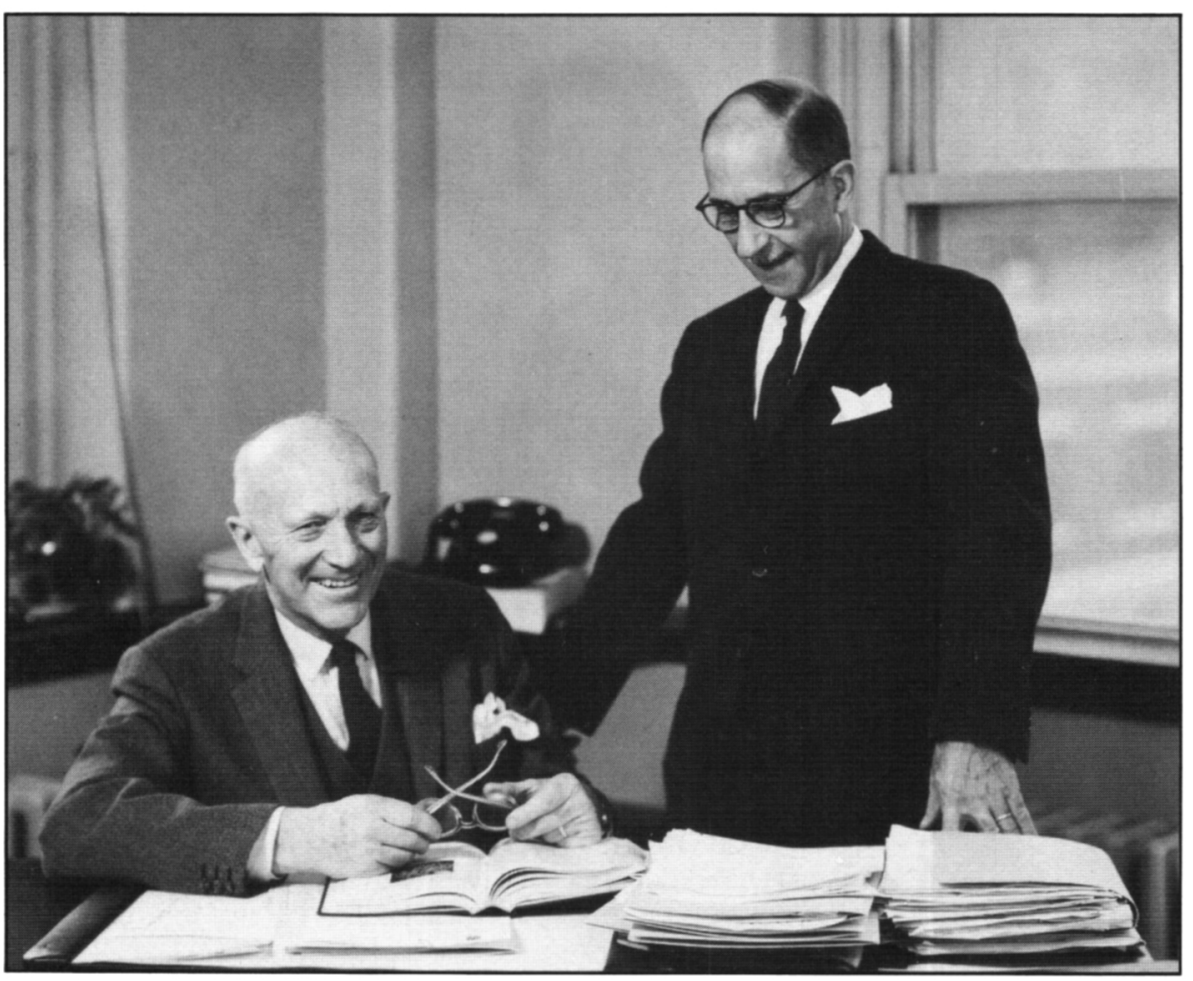

Figure 5-Dr. Penfield and Dr. Jasper upon completion of their book. "Epilepsy and the Functional Anatomy of the Human Brain" published in 1954. 
cal procedures in conscious patients, and our laboratory studies of experimental epilepsy, studies of cerebral circulation and pathology of epileptogenic lesions and methods of treatment in the book entitled "Epilepsy and the Functional Anatomy of the Human Brain" published by Little Brown and Co. Boston, in 1954. A photograph taken upon the completion of this manuscript is shown in Fig. 5.

There were also important developments in neuropsychology led by Donald Hebb, which included pioneer studies of the effects of sensory deprivation, and the work of Jim Olds and Peter Milner on the development of the technique of selfstimulation for the study of mechanisms of motivation in experimental animals. Brenda Milner then joined the staff of the MNI in 1950, from Cambridge, England via the University of Montreal, to begin her classical studies of memory deficits in patients with temporal lobe excisions, and the careful psychological analysis of a variety of other deficits in speech, and other perceptual and motor functions in patients undergoing circumscribed removals of specific regions of the cerebral cortex during neurosurgical procedures, mainly for the treatment of focal epilepsy. She attracted numerous coworkers and has received worldwide recognition for her continuing important contributions to neuropsychology in relation to local cortical function in man. Among these honours was the K.S. Lashley prize of the American Philosophical Society, Fellowship in the Royal Society of Canada and London, and the Killam prize for outstanding research in Canada.

Important also in the rapid development of neuroscience in Montreal during the 10-15 years following the war was the arrival of Charles Leblond from France to the chair of Anatomy at McGill. Charles Leblond introduced radioautography for the study of developmental neuroanatomy with the use of radioactive thymidine, and the use of tritiated amino acids and axonal flow for the tracing of anatomical pathways in the nervous system, in collaboration with Bernard Droz, a graduate student from France. Radioautography was also used for the analysis of neuronal-glial interactions in collaboration with Jean Patterson during her postgraduate studies at McGill before taking her position in the Anatomy Department of the University of Manitoba.

Another important development in these early years following the war was the return of Theodore Sourkes to establish neuropharmacological laboratories in the Research Institute of the Allan Memorial Institute of Psychiatry at McGill. Ted Sourkes had received his training in biochemistry at Queens and McGill, and at the Merck Laboratories in New Jersey. He studied catecholamine metabolism in a variety of mental diseases, summarized in his book "The Biochemistry of Mental Disease".
He then turned his attention to dopa-dopamine metabolism in Parkinson's disease. In collaboration with André Barbeau and Louis Poirier of the University of Montreal he was able to show that there was a dopamine deficiency in patients with Parkinson's disease, leading to early attempts at treatment with L-dopa. Louis Poirier, at the Université de Montréal, developed the first good experimental model of the Parkinson syndrome, as well as other motor disturbances, in the monkey. Sourkes and Poirier were then able to show that there was a depletion of dopamine in the caudate and putamen in the affected monkeys, and showed with Poirier that there was a dopaminergic tract from the substantia nigra to the striatum which had not been described by anatomists at the time.

In 1948, a neuroanatomist from Holland, Prof. J. Auer, established a department at the University of Ottawa, continuing his studies of the hypothalamus. He developed a research group there and recruited Marc Colonnier, who, after receiving graduate training in electron microscopy with Gray in London, returned to become one of Canada's leading neuroanatomists, at the University of Montreal, the University of Ottawa, and at Laval University in Québec.

I am afraid that I have now extended the constraints of this report, and have given only a partial picture of the early development of neuroscience in Canada leading up to the 25th Anniversary in 1959 of the founding of the MNI. My report is also biased by personal experiences which I have been kindly encouraged to include by my colleagues who invited me to write up this lecture for publication. I wish to apologize for many important omissions which should have been included had there been more time and space.

During the past 20-25 years neuroscience has flourished in Ontario and Québec, as elsewhere, with Canada playing an important role in these worldwide developments. There are now 214 members of the Society for Neuroscience in Ontario and Québec, 165 from Québec alone. The Canadian branch of the society can well be proud of their contributions to these rapid developments. Certainly I am very proud, pleased, and grateful for the forty-eight years I have been privileged to take part in these exciting developments of neuroscience in Canada where my family and I have enjoyed such warm hospitality and friendship, and where life outside the laboratories has been full of beautiful and rewarding experiences.

There can be no doubt that the Montreal Neurological Institute played a leading role in these early developments. Dr. Wilder Penfield's creative inspiration has succeeded in establishing a Canadian Institute which has played an important role in the development of both clinical and basic neuroscience in North America with widespread influences throughout the world. 